\title{
A Method for 3D Reconstruction of the Ming and Qing Official-Style Roof Using a Decorative Components Template Library
}

\author{
Pengpeng Huo ${ }^{1,2,3,4}$, Miaole Hou ${ }^{1,2}\left(\right.$ ) , Youqiang Dong ${ }^{1,2, *}$, Aiqun Li ${ }^{5}$, Yuhang $\mathrm{Ji}^{1,2}$ \\ and Songnian $\mathrm{Li}^{6}$ (D) \\ 1 School of Geomatics and Urban Spatial Informatics, Beijing University of Civil Engineering and Architecture, \\ Beijing 100044, China; 2208521518001@stu.bucea.edu.cn (P.H.); houmiaole@bucea.edu.cn (M.H.); \\ 2108521519033@stu.bucea.edu.cn (Y.J.) \\ 2 Key Laboratory for Architectural Heritage Fine Reconstruction \& Health Monitoring, Beijing 100044, China \\ 3 Beijing Institute of Surveying and Mapping, Beijing 100038, China \\ 4 Beijing Key Laboratory of Urban Spatial Information Engineering, Beijing 100038, China \\ 5 School of Civil and Transportation Engineering, Beijing University of Civil Engineering and Architecture, \\ Beijing 100044, China; liaiqun@bucea.edu.cn \\ 6 Department of Civil Engineering, Ryerson University, Toronto, ON M5B 2K3, Canada; snli@ryerson.ca \\ * Correspondence: dongyouqiang@bucea.edu.cn; Tel.: +86-10-6120-9338
}

Received: 9 August 2020; Accepted: 28 September 2020; Published: 29 September 2020

\begin{abstract}
The ancient roof decorative components of the official-style architectures from the Ming and Qing dynasties in China hold both physical and symbolic significance. These roof structures are the essential objects in three-dimensional (3D) modeling of ancient architectures for traditional Chinese cultural preservation. Although ancient architectures can be surveyed by a 3D laser scanner, the complex geometry and diverse pattern of their roof decorative components make the 3D point cloud reconstruction challenging, or at some points, nearly impossible in a fully automated manner. In this paper, we propose a method to ensure that the 3D shape of each roof decorative component is accurately modeled. First, we establish a decorative components template library (or "template library" in short hereafter), which is the first of its kind for the roofs of Ming and Qing official-style architectures. The process of establishing the decorative components template library begins with a remote collection of survey data using a terrestrial laser scanner and digital camera. The next stage involves the design and construction of different $3 \mathrm{D}$ decorative components in the template library with reference to the manuscripts written in the Ming and Qing dynasties' architectural pattern books. With the point cloud data collected on any Ming and Qing official-style architecture, we further propose a geo-registration mechanism to search for an optimal fitting of the decorative components from the template library on the collected point cloud automatically. Based on the experimental results, the accuracy of point cloud registration yields less than $0.02 \mathrm{~m}$, which meets the accuracy of the 3D model at LoD 300 level. Time consumption is less than 5 s and stable, for large volume computing capacity has good robustness. The proposed strategy provides a new way for the 3D modeling of large and clustered historical architectures, particularly with complex structures.
\end{abstract}

Keywords: official-style architecture; decorative components; template library; point cloud registration; level of details; BIM; 3D modeling

\section{Introduction}

The Ming and Qing dynasties (1368-1912) were the last feudal period in China. In this period, the hierarchy was strictly divided, and the construction method of royal residence was unified, 
which created a unique official-style architecture system. The Ming and Qing official-style architectures, which are considered as the last peak of Chinese architectural history, are an important carrier of traditional Chinese culture [1]. The protection of these ancient architectures is imminent due to the occurrence of natural disasters and man-made destruction. Traditional documentation methods of the Ming and Qing official-style architectures mainly rely on the use of paper documents (including paintings and tables), two-dimensional (2D) digital images, and so on. A paper document tends to be abstract and is unable to reflect the detail geometry of the architecture. Additionally, a large batch of storage results in inconvenient information retrieval. Although 2D digital images have the privilege of intuitive display, it is mostly impossible to perform geometric measurements or retrieve the dimension of the objects. Therefore, all these approaches are unable to provide reliable data support for reconstruction and restoration, and it is not conducive to serve the purpose of accurate preservation and scientific research. With the development of digital technology, especially the emergence of the three-dimensional (3D) laser scanners (or LiDAR), digital preservation has become viable for the Ming and Qing official-style architectures [2-4]. Nevertheless, the unstructured and bulky 3D point clouds require intensive post processing. It thus gives rise to certain challenges-for example, transforming the unstructured 3D point clouds into a digital 3D model for subsequent analysis and cultural heritage management.

The use of point clouds for 3D reconstruction can be commonly divided into three categories: data-driven methods [5-7], model-driven methods [8-10] and knowledge-driven methods [11-13]. Studies in $[14,15]$ provide comprehensive reviews regarding the results of $3 \mathrm{D}$ building reconstruction using point clouds. Comparing to modern buildings, the structure of historic architecture is rather complex and heterogeneous. Therefore, it is mostly impossible to adopt any one of the aforementioned methods to generate an accurate 3D model for historic architecture. Thus, integrated methods are proposed in order to overcome the limitations [16-18]. In [19], two types of Milan Cathedral's main spire structure were individually reconstructed using different methods. The first type are mostly regular shapes, they were reconstructed by a model-driven method. The second type of structure consisted of flower decorations or artistic components, which cannot be modeled using parameters. Thus, these components were represented by 3D mesh models based on the data-driven method. The final digital 3D model of Milan Cathedral's main spire was generated by merging these two types of components. In [20], a similar method is also applied to the loggia of Castel Masegra (Sondrio, Italy). For regular and irregular shapes, existing libraries and Non-Uniform Rational B-Splines (NURBS) are used for 3D reconstruction, respectively. Although such an integrated method can also be adopted for the reconstruction of the Ming and Qing official-style architectures, this approach heavily relies on manual intervention and is time consuming. Hence, an automatic 3D reconstruction approach for the Ming and Qing official-style architectures is still desired.

As shown in Figure 1, the Ming and Qing official-style architectures mainly consist of four parts: (1) platform or stylobate, (2) column or wall, (3) Dou-gong and (4) roof [21]. The components of each part can be further divided into two categories: regular components and irregular components. Generally speaking, the regular components have well-defined characteristics and follow the potential geometric relationship [22,23]. Taking the roof structure as an example, it is mainly composed of ridge, tile and decorative components. The section shape of the semicircular tile is a half-round ridge, where the section shape of the board tile is one-eighth round [24]. The geometric features, such as straight-line segments, curve and plane, can facilitate automatic 3D model construction from the point cloud and/or image with the aid of this prior information. The irregular components mainly contain the decorative components, especially the roof decorative components, which are hard to model based on the geometric features. Hence, the mesh model is still needed in the process of 3D modeling. Since the data points corresponding to the decorative components cannot be completely segmented, this makes automatic reconstruction more challenging. To overcome this problem, it thus inspires us to create a new template library for each decorative component. After the decorative components are detected in the collected point clouds of any Ming and Qing official-style architectures, the 3D model of the 
detected decorative component from the pre-defined template library can be directly applied after the rigid transformation. This not only reduces the 3D modeling work of repetitive complex type components, save computational resources, but also better ensures the accuracy of the constructed model. There is no denying that establish a template library requires a great deal of preparation, including the inevitable manual modeling effort, and that getting the template library to cover the full range of components will be a challenging task. However, since the decorative components on the roof of the Ming and Qing, official-style architectures are highly similar and with a limited number of types, the constructed template library can be universally adopted on any Ming and Qing official-style architectures.

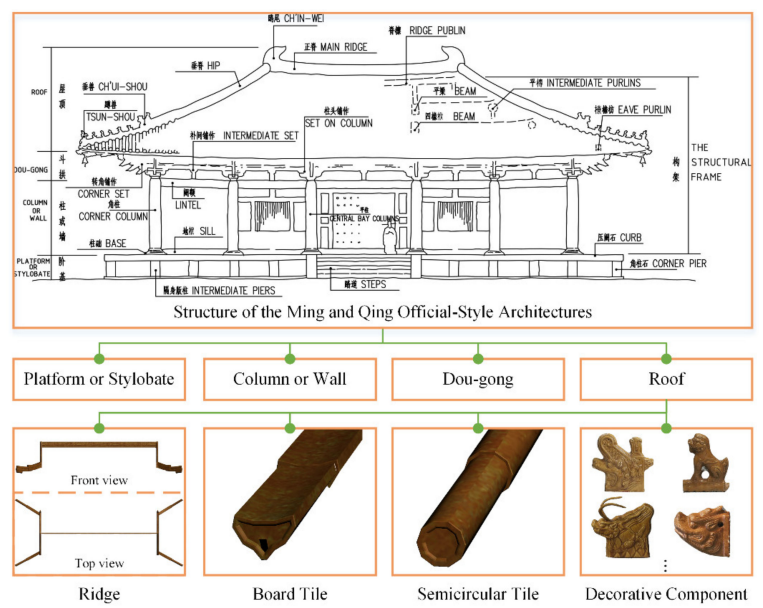

Figure 1. Decomposition of the Ming and Qing official-style architecture structures [21].

A similar approach for constructing a template library can be found in [25-28] (see Table 1). Most of the existing template libraries do not bundle with an automatic mechanism of identifying components. Instead, the majority of them rely on manual operation to identify a specific component type, and subsequently let the operator perform "drag and drop" in order to align the component into the corresponding location. Although this method ensures the accuracy of the reconstructed 3D model, its efficiency is limited. Therefore, having an automatic 3D reconstruction with reference to the decorative component template library is sound, particularly for the large number of existing and complex structure of the Ming and Qing official-style architectures.

Table 1. A comparison of existing template library used in 3D reconstruction.

\begin{tabular}{|c|c|c|c|c|c|}
\hline Study & Object Type & Basis for Library & Software/Tools & Method of Application & Analysis \\
\hline $\begin{array}{c}\text { Zdeněk } \\
\text { Poloprutský } \\
\text { [24] }\end{array}$ & $\begin{array}{c}\text { Coaching inn in } \\
\text { Kostelec nad Vltavou } \\
\text { (Písek District, Czech } \\
\text { Republic) }\end{array}$ & $\begin{array}{l}\text { Surveying data (Photo } \\
\text { documentation, point } \\
\text { cloud and drawings) }\end{array}$ & $\begin{array}{l}\text { Autodesk Revit } \\
\text { software }\end{array}$ & / & $\begin{array}{l}\text { This modeling method } \\
\text { can design a library } \\
\text { usable for detailed BIM } \\
\text { models. }\end{array}$ \\
\hline $\begin{array}{l}\text { Murphy } \\
{[25]}\end{array}$ & $\begin{array}{l}\text { European classical } \\
\text { architecture }\end{array}$ & $\begin{array}{l}\text { Vitruvius to the 17th } \\
\text { and 18th century } \\
\text { Architectural Pattern } \\
\text { Books }\end{array}$ & $\begin{array}{l}\text { GDL embedded in } \\
\text { the Graphisoft } \\
\text { ArchiCAD. } \\
\text { Decoration and } \\
\text { non-uniform shapes } \\
\text { based on NURBS, } \\
\text { meshing and } \\
\text { Boolean operations }\end{array}$ & $\begin{array}{c}\text { The library is designed } \\
\text { as a plug-in for existing } \\
\text { software platforms for } \\
\text { mapping these objects } \\
\text { onto point clouds and } \\
\text { image surveys. }\end{array}$ & $\begin{array}{l}\text { Placing a construction } \\
\text { element or GDL object, } \\
\text { the default parameters } \\
\text { need to be manually } \\
\text { edited in order to } \\
\text { correspond with the } \\
\text { survey data. }\end{array}$ \\
\hline $\begin{array}{l}\text { A. Baik } \\
{[26]}\end{array}$ & $\begin{array}{l}\text { Old Jeddah historical } \\
\text { buildings }\end{array}$ & $\begin{array}{l}\text { Laser scanning point } \\
\text { clouds and } \\
\text { photogrammetric } \\
\text { survey }\end{array}$ & $\begin{array}{c}\text { Modeling library } \\
\text { elements in 3D } \\
\text { modeling software } \\
\text { such as Autodesk } \\
\text { Revit and Rhinoceros }\end{array}$ & $\begin{array}{l}\text { The library is used as } \\
\text { plug-in of existing BIM } \\
\text { software platforms such } \\
\text { as Autodesk Revit. }\end{array}$ & $\begin{array}{l}\text { Determining the } \\
\text { accurate position of the } \\
\text { object's elements } \\
\text { requires preprocessing. }\end{array}$ \\
\hline $\begin{array}{c}\text { C Dore } \\
{[27]}\end{array}$ & Building facades & $\begin{array}{l}\text { Laser scanning, } \\
\text { photogrammetric data, } \\
\text { and references to } \\
\text { Vitruvius to Palladio to } \\
\text { the architectural } \\
\text { pattern books of the } \\
\text { eighteenth century }\end{array}$ & $\begin{array}{l}\text { Parametric objects } \\
\text { were built using GDL } \\
\text { embedded in the } \\
\text { ArchiCAD BIM } \\
\text { software }\end{array}$ & $\begin{array}{l}\text { Automatically position } \\
\text { library components } \\
\text { based on architectural } \\
\text { rules and proportions, } \\
\text { but manually resize and } \\
\text { plot the components. }\end{array}$ & $\begin{array}{l}\text { Users have a full control } \\
\text { over the global and local } \\
\text { facade for simple } \\
\text { structure components. }\end{array}$ \\
\hline
\end{tabular}




\section{Method}

In this study, the contributions are twofold. First, we establish a decorative component template library, which is the first of its kind for the roofs of Ming and Qing official-style architectures. The library development is based on several studies that constructed decorative components and template libraries for different architectures [29-31]. Second, this template library can be used to automatically reconstruct 3D roof decorative components of any Ming and Qing official-style architecture based on a geo-registration mechanism.

After the template library was constructed, a geo-registration mechanism based on object identification and point cloud matching is proposed for 3D reconstruction. In this process, each decorative component can be positioned, located and scaled automatically in accordance with the architectural rules and proportions, and thus the process is instructive for other similar work. The automatic geo-registration mechanism is divided into four steps (see Figure 2). First, the corresponding decorative component type is detected based on the "You Only Look Once v3" (YOLOv3) algorithm [32]. Second, the corresponding decorative component model from the template library is transformed into a 3D point cloud. Third, a coarse registration based on the Sample Consensus Initial Alignment (SAC-IA) algorithm [33] is performed. Fourth, a fine registration based on the Scaling Iterative Closest Point (SICP) algorithm [34] is performed. The YOLOv3 detection results are further filtered by the following criteria: (1) if the confidence coefficient of the YOLOv3 detection result is greater than the set threshold, then the subsequent point cloud registration will be carried out directly; (2) if the confidence coefficient of the YOLOv3 detection results is less than the set threshold, then the first three results with the highest confidence coefficient are selected for point cloud registration. The object whose registration result reaches the preset accuracy value and performs best is regarded as successful; (3) if it does not conform to 1 and 2, it will be considered as a failure. The operation of this component will be skipped directly.

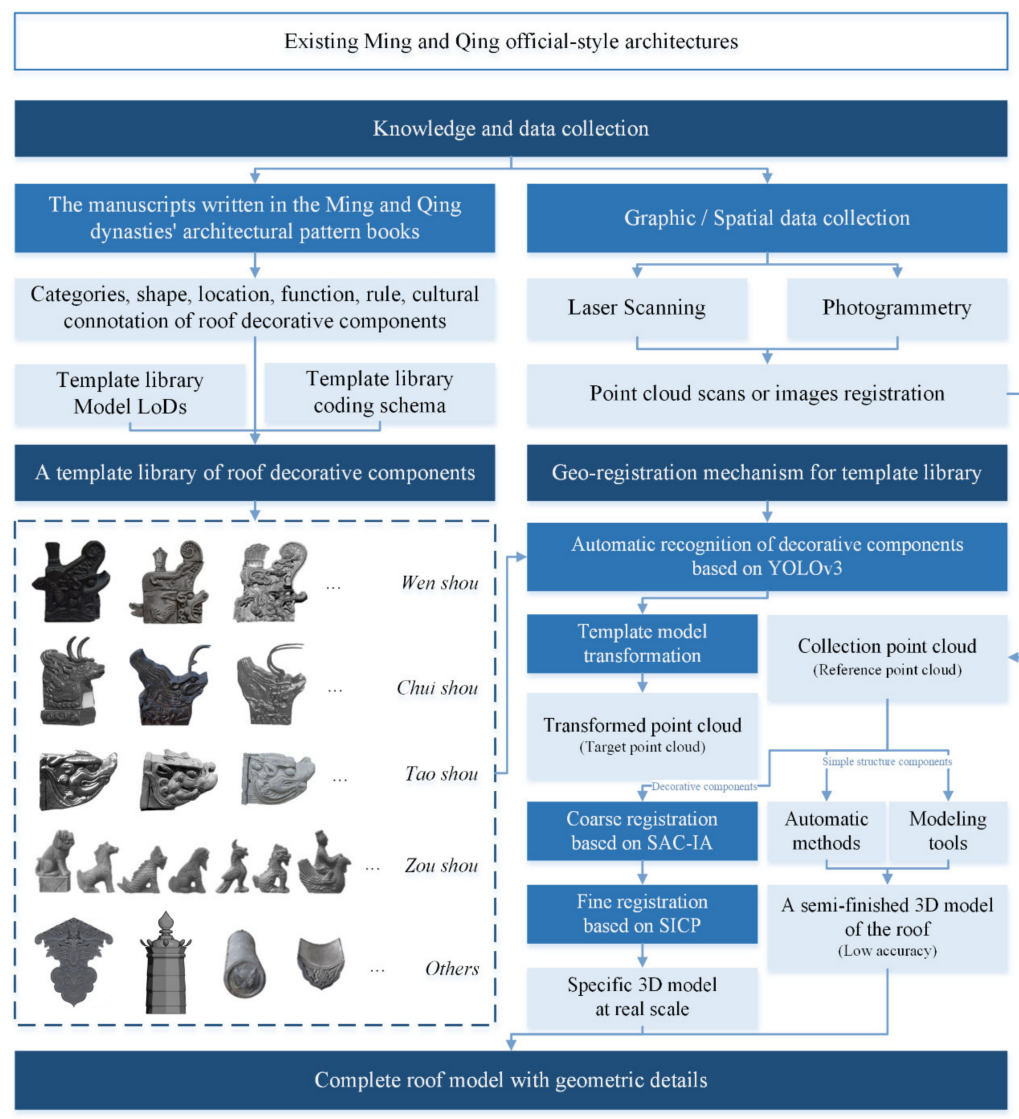

Figure 2. The workflow for reconstructing 3D roof model using the template library. 


\section{A Template Library of Roof Decorative Components}

The understanding of the roof decorative components is an important prerequisite for the establishment of the decorative component template library which include their category, shape, location, function, rule, and cultural connotation. These are required to reconstruct the roof according to the architectural pattern books and manuscripts (see Section 3.1. for more details). In this template library, the coarse 3D model of decorative components is reconstructed based on point cloud data with the aid of photogrammetric computer vision or laser scanning technology. The collected point cloud can be classified into two main categories: dense image matching (DIM) point cloud and laser scanning point cloud. Subsequently, the roof decorative components in the 3D model are refined with reference to the design and detail listed in the architectural pattern books and manuscripts using 3D modeling software. These roof decorative components are then stored in the template library following a pre-defined coding schema. In general, this strategy is not bound by historic architecture. It also applies to any type of building with specific design rules so that a corresponding template library can be established accordingly.

\subsection{An Overview of Roof Decorative Components in the Template Library}

The "Qing Structural Regulations", compiled by SiCheng Liang in 1934, lists the details of the Ming and Qing official-style architectures, including the construction method, layout, shape and structure of the buildings, as well as the name, dimension, topology and function of each component [35]. As shown in Figure 3, the roof can be classified into five main categories according to the structure, which are hip roof, gable-and-hip roof, pyramidal roof, overhanging gable roof, and flush gable roof (Figure 3a-e). The hip roof, gable-and-hip roof, and pyramidal roof can be further divided into double-eave and single-eave (Figure $3 \mathrm{f}-\mathrm{h}$ ). Moreover, the gable-and-hip roof, gable roof, and overhanging gable roof can derive another type of round ridge roof (Figure 3i). These roofs not only inherit the style of the Ming and Qing official-style architectures but also represent the social hierarchy of the inhabitants. From a high to low rank, the roof type is double-eave hip roof, double-eave gable-and-hip roof, double-eave pyramidal roof, hip roof, gable-and-hip roof, pyramidal roof, overhanging gable roof, round ridge roof, and flush gable roof [21].

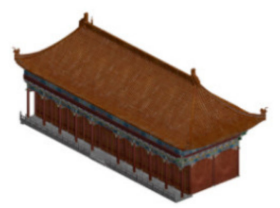

(a)

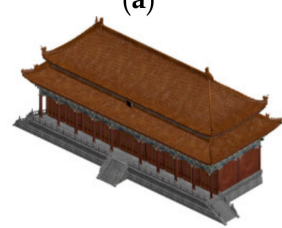

(f)

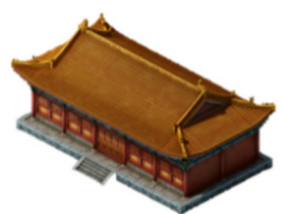

(b)

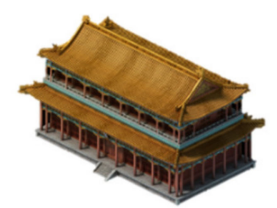

(g)

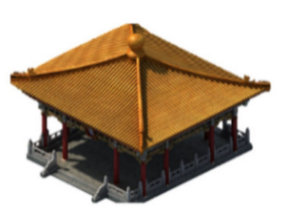

(c)

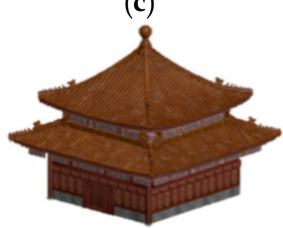

(h)

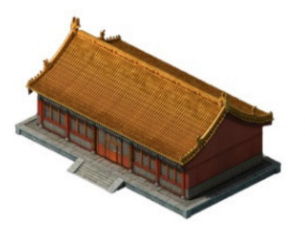

(d)

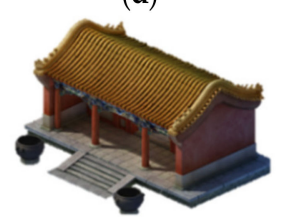

(i)

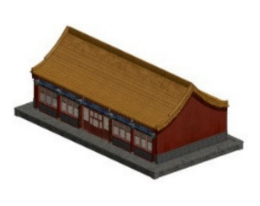

(e)

Figure 3. The roof types: (a) hip roof; (b) gable-and-hip roof; (c) pyramidal roof; (d) overhanging gable roof; (e) flush gable roof; (f) double-eave hip roof; (g) double-eave gable-and-hip roof; (h) double-eave pyramidal roof; (i) round ridge roof.

With reference to the template library, the procedure of 3D modeling the roofs of Ming and Qing official-style architectures follows certain rules and schemes [36]. First, the number of roof decorative components located on different types of roof is specified. For instance, the Hall of Supreme Harmony in Forbidden City (Beijing, China) is the highest-grade Ming and Qing official-style architecture, and the roof type is double-eave hip. The number of Zou shou, which is a divine creature on the roof ridge that is said to ward off evil, is ten. Since the grade of the other Ming and Qing official-style architectures is 
lower, the number of Zou shou, which can only be nine or less, has to be an odd number [37]. In addition, some roof decorative components can only be found on a specified type of roof. We thus divide the roof decorative components into five categories: Chui shou, Tao shou, Wen shou, Zou shou and other types of decorative components (see Figure 2) according to historical records, especially the records from the Qing Dynastic Ministry of Works [38]. These specific rules and proportions outlined in the manuscripts related to the official-style architectures can provide an initial estimate of the position and size of the roof decorative components. This prior knowledge certainly helps reduce the amount of further editing when performing a digital 3D modeling of the official-style architectures from the collected data and facilitates the possibility to use the template library automatically.

\subsection{Construction of the Template Library}

The Ming and Qing official-style architectures are composed by different complicated and irregular components. The constructed 3D model in the proposed template library should possess different levels of detail (LoDs) that can be used to serve different purposes. For roof decorative components, they need to be accurately and adequately represented so that the geometry, attribute, and parameter proportion are preserved. Therefore, the LoDs and the desired accuracy of these components should be determined before creating the template library.

In terms of modeling the buildings, previous studies [39] mostly followed the standardized protocol of LoDs in Building Information Modeling (BIM) defined by the American Institute of Architects to specify the LoD of 3D architectural models [40], although some studies followed the level of geometry [41,42] and the grades of generation [43]. Similarly, we also classify the 3D model into five LoDs (see Table 2). LoD 100 models the decorative components using 2D historical manuscripts and pattern books without accurate parameter information. LoD 200 describes the outline of decorative components by prismatic extrusion solid with certain parameter information. LoD 300 represents the character of decorative components by the collected data (point cloud or digital image), and the outline is represented by either a Delaunay triangular mesh or raster data. At LoD 400, the external geometric form is represented by detailed surfaces and shapes, allowing the proper orientation of Heritage Building Information Models (HBIMs) for in-depth BIM-based analyses. LoD 500 provides the geometric details of external and internal forms and new levels of information sharing for different purposes.

Table 2. The description and accuracy of the level of details.

\begin{tabular}{ccc}
\hline Level of Details & Accuracy of Planar/Elevation & Scale \\
\hline LoD 100 & - LoD200 & $/$ \\
LoD 200 & $0.05 \mathrm{~m} / 0.05 \mathrm{~m}$ & $1: 500$ \\
LoD 300 & $0.02 \mathrm{~m} / 0.02 \mathrm{~m}$ & $1: 200$ \\
LoD 400 & $0.01 \mathrm{~m} / 0.01 \mathrm{~m}$ & $1: 100$ \\
LoD 500 & $0.005 \mathrm{~m} / 0.005 \mathrm{~m}$ & $1: 50$ \\
\hline
\end{tabular}

Brumana et al. [44] discussed the HBIM level of detail-geometry-accuracy. In their work, they adopted a scale ranging from 1:1000 to 1:10. As a result, the models of decorative components at LoD 100 to LoD 200 do not have shapes in detail. Hence, the accuracy of the decorative components in the template library should not be less than that of $\operatorname{LoD} 300(\leq 0.02 \mathrm{~m})$, which corresponds to the scale of 1:200. This thus meets the need for 3D reconstruction of the roof of the Ming and Qing official-style architectures.

After the desired accuracy is defined, the following method was applied to construct each decorative component in the template library. The library components were first generated from the DIM point clouds that represent the geometry and fabric of the roof decorative components, and the Delaunay triangulation was implemented to automatically reconstruct the 3D mesh models. Three-dimensional mesh can be used to reconstruct standard shapes (lines, circles, parabolas, etc.) or free-form profiles. 
However, such an automatic reconstruction is unlikely to meet the expected accuracy requirements. In addition, the details of decorative components cannot be revealed. Therefore, we imported the 3D mesh models into the Autodesk 3Ds Max software and performed manual editing on the model with reference to their materials, historical research, existing drawings and pictures.

An example of the reconstruction of decorative components is illustrated in Figure 4. This complex component represents the Wen shou, which is usually located on either side of the main ridge. Ribs have a circular structure that can be reconstructed with manual measurements on the point cloud. This allows a geometric reconstruction that preserves the uniqueness in terms of both component style and structure. The proposed approach can be summarized as follows:

- Acquisition and registration of the decorative component's point cloud (Figure 4a);

- Surface generation using the point cloud and the mesh network (Figure $4 b$ );

- Construction of a 3D model by editing the mesh model with a manual, semiautomated or automated approach (Figure 4c).

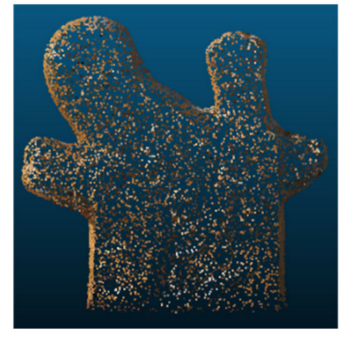

(a) Point Cloud

acquisition and registration

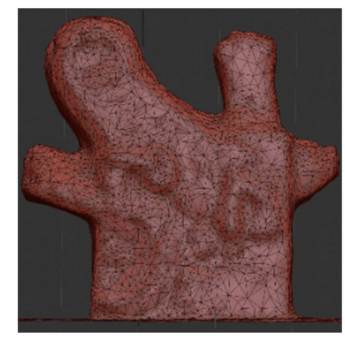

(b) Automated Mesh surface generation

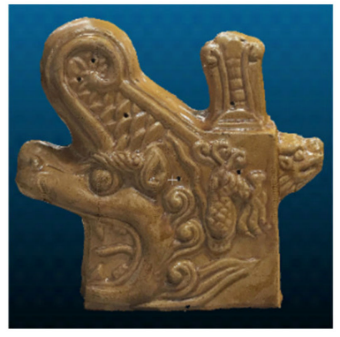

(c) Shape

3D model

Figure 4. The workflow of decorative component reconstruction (Wen shou).

At present, this template library includes 105 models of decorative components, which are located in different regions of China and built by following the construction style of the Ming and Qing dynasties. Among them, the official-style decorative components are divided into five most representative types-Chui shou (16), Tao shou (12), Wen shou (18), Zou shou (32) and other types of decorative components (27), as described in Table 3.

Table 3. The main roof decorative components of the Ming and Qing official-style architectures.

\begin{tabular}{|c|c|c|c|c|c|}
\hline Categories & Shape & Location & Function & Rule & Cultural Connotation \\
\hline Chui shou & & $\begin{array}{l}\text { The Chui shou } \\
\text { is behind the } \\
\text { Zou shou. }\end{array}$ & $\begin{array}{l}\text { The Chui shou is } \\
\text { also used to cover } \\
\text { and decorate the } \\
\text { iron nails that } \\
\text { prevent the vertical } \\
\text { ridge tiles from } \\
\text { slipping and } \\
\text { reinforce the roof } \\
\text { ridges }\end{array}$ & $\begin{array}{l}\text { Both the levels of Zou shou } \\
\text { and Chui shou are the same. } \\
\text { The height of the Chui shou } \\
\text { is } 1.5 \text { times to the height of } \\
\text { the forehead height, and } \\
\text { the width to height ratio is } \\
1 \sim 1.2 \text { to } 1 .\end{array}$ & l \\
\hline Tao shou & & $\begin{array}{l}\text { The Tao shou } \\
\text { is located at } \\
\text { the top of the } \\
\text { wing corner } \\
\text { beam or } \\
\text { corner beam. }\end{array}$ & $\begin{array}{l}\text { The Tao shou is } \\
\text { responsible for } \\
\text { waterproofing and } \\
\text { decoration. }\end{array}$ & $\begin{array}{l}\text { The Tao shou has a } \\
\text { height-to-length ratio of } 1 \\
\text { to } 1.4 \text {, and its thickness is } \\
\text { consistent with height. } \\
\text { The shape usually is a lion } \\
\text { or the head of a dragon. }\end{array}$ & $\begin{array}{l}\text { According to ancient Chinese } \\
\text { legend, Tao shou can protect } \\
\text { homes from fire. }\end{array}$ \\
\hline Wen shou & & $\begin{array}{l}\text { The Wen shou } \\
\text { is located } \\
\text { above the } \\
\text { midline of the } \\
\text { ridge, and at } \\
\text { the ends of } \\
\text { the main } \\
\text { ridge }\end{array}$ & $\begin{array}{l}\text { Seal the gap of the } \\
\text { tile ridge to avoid } \\
\text { water seepage, } \\
\text { enhance the } \\
\text { stability of the } \\
\text { main ridge, and } \\
\text { promoted the } \\
\text { Tenon-and-mortise } \\
\text { structure to be } \\
\text { tightly joined. }\end{array}$ & $\begin{array}{l}\text { The levels of the wen shou } \\
\text { and the main ridge are the } \\
\text { same. When the } \\
\text { architecture has double } \\
\text { eaves, the level of the wen } \\
\text { shou can be one level } \\
\text { higher than the main ridge. } \\
\text { The width to height ratio } \\
\text { of the Wen shou is } 7 \text { to } 10 \text {. }\end{array}$ & $\begin{array}{l}\text { The moral of the Wen shou is to } \\
\text { protect the family rich in food and } \\
\text { clothes and has a large population, } \\
\text { and Wen shou can also keep their } \\
\text { homes safe in legend. }\end{array}$ \\
\hline
\end{tabular}


Table 3. Cont.

\begin{tabular}{|c|c|c|c|c|c|}
\hline Categories & Shape & Location & Function & Rule & Cultural Connotation \\
\hline Zou shou & & $\begin{array}{l}\text { Zou shou is } \\
\text { distributed in } \\
\text { the lower half } \\
\text { of the vertical } \\
\text { ridge. } \\
\text { Celestial being } \\
\text { is usually } \\
\text { located above } \\
\text { the hooks at } \\
\text { the corners of } \\
\text { the roof, with } \\
\text { Zou shou } \\
\text { behind it. }\end{array}$ & $\begin{array}{l}\text { The tiles of the } \\
\text { vertical ridge are } \\
\text { fixed with iron } \\
\text { nails to prevent } \\
\text { slipping, and the } \\
\text { Zou shou is used to } \\
\text { cover and decorate } \\
\text { the iron nails. }\end{array}$ & $\begin{array}{l}\text { The width to height ratio } \\
\text { of the Zou shou is about } 4 \\
\text { to } 10 \text { more than } 6 \text { to } 10 \text {, } \\
\text { and the ratio of thickness } \\
\text { to eyebrow height is } 3 \text { to } \\
10 \text {. According to the social } \\
\text { hierarchy of the occupants } \\
\text { to determine the number } \\
\text { of placements. The total } \\
\text { number is usually singular } \\
\text { (not containing the } \\
\text { Celestial man). The order } \\
\text { of arrangement is Dragon, } \\
\text { Phoenix, Lion, Tian ma, } \\
\text { Hai ma, Suan ni, Xia yu, } \\
\text { Xie zhi, Dou niu, and } \\
\text { Xingshi. }\end{array}$ & $\begin{array}{l}\text { Dragon, a legendary creature that } \\
\text { can thrive in clouds and rain, and } \\
\text { is a symbol of imperial power; } \\
\text { Phoenix, a metaphor for a person } \\
\text { with virtue, is also the name of a } \\
\text { queen; } \\
\text { Lion, the guardian of Buddhism, a } \\
\text { symbol of bravery and majesty. } \\
\text { Tian Ma, a loyal beast, chasing the } \\
\text { wind; } \\
\text { Hai Ma, the brave beast, enters } \\
\text { the sea and enters the abyss. } \\
\text { Suan Ni, playing the role of the } \\
\text { mighty beast; } \\
\text { Xia Yu, strange beast in the sea, } \\
\text { making clouds rain, firefighting, } \\
\text { and disaster prevention; } \\
\text { Xie Zhi, brave and fair, implying } \\
\text { justice and fairness; } \\
\text { Dou Niu, a mascot for disaster } \\
\text { elimination; } \\
\text { Xing Shi, a bi-winged monkey } \\
\text { statue, magic reduction, and } \\
\text { lightning protection, is the last } \\
\text { beast. }\end{array}$ \\
\hline Others & & $\begin{array}{l}\text { Wa dang, } \\
\text { Xuan yu and } \\
\text { tiles. }\end{array}$ & $\begin{array}{l}\text { It not only } \\
\text { reinforces the roof } \\
\text { structure; they also } \\
\text { deemed to be an } \\
\text { important carrier } \\
\text { of Chinese folklore. }\end{array}$ & l & $\begin{array}{l}\text { People place their hopes on } \\
\text { decorative components, looking } \\
\text { forward to every family's peace, } \\
\text { and prosperity, health, and } \\
\text { happiness. }\end{array}$ \\
\hline
\end{tabular}

\subsection{Template Library Coding Schema}

A hierarchical coding schema is introduced in the template library in order to efficiently manage the components according to the rules of the Ming and Qing official-style architectures. As shown in Figure 5, the code of the decorative components consists of three blocks: the rigid code, flexible code and flow code. The rigid code defines the Ming and Qing official-style architectural style by the type of roof, as listed in Table 4. The flexible code is divided into three levels, as shown in Table 5. The first-level code is named by a capital English letter, indicating the reconstruction object that belongs to a certain part of the Ming and Qing official-style architectures. The second-level code is named by two capital English letters, indicating the specific structure, and the third-level code refers to the name of the decorative components. The flow code can be used to represent variations of the same category of decorative components.

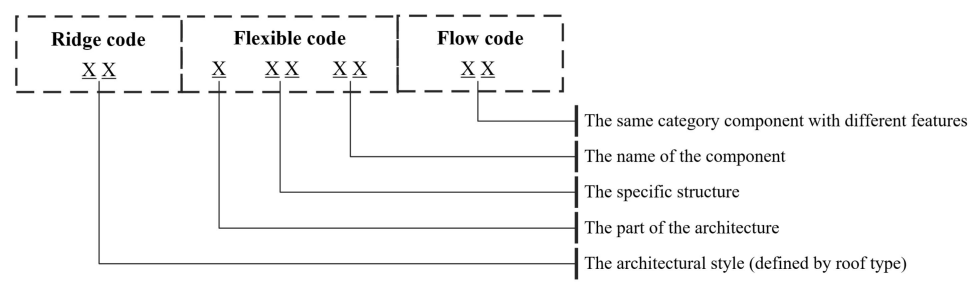

Figure 5. The codes of roof decorative components.

Table 4. Design of rigid code.

\begin{tabular}{cccc}
\hline Type of Roof & Code & Type of Roof & Code \\
\hline double-eave hip roof & DH & pyramidal roof & SP \\
double-eave gable-and-hip roof & DG & overhanging gable roof & SO \\
double-eave pyramidal roof & DP & gable roof & SG \\
hip roof & SH & flush gable roof & SF \\
gable-and-hip roof & SA & & \\
\hline
\end{tabular}


Table 5. Design of flexible code.

\begin{tabular}{|c|c|c|c|c|c|}
\hline First-Level C & & \multicolumn{2}{|c|}{ Second Level-Code } & \multicolumn{2}{|c|}{ Third-Level Code } \\
\hline \multirow{4}{*}{ Platform or Stylobate } & \multirow{4}{*}{$\mathrm{P}$} & Intermediate pier & IP & \multirow{4}{*}{$\cdots$} & \\
\hline & & Step & ST & & \\
\hline & & Curb & $\mathrm{CU}$ & & \\
\hline & & Corner pier & $\mathrm{CP}$ & & \\
\hline \multirow{6}{*}{ Column or Wall } & \multirow{6}{*}{$\mathrm{C}$} & Corner column & $\mathrm{CC}$ & \multirow{6}{*}{\multicolumn{2}{|c|}{$\cdots$}} \\
\hline & & $\begin{array}{l}\text { general bay } \\
\text { column }\end{array}$ & GB & & \\
\hline & & Base & BA & & \\
\hline & & Sill & SI & & \\
\hline & & Wall & WA & & \\
\hline & & Window & WI & & \\
\hline \multirow{3}{*}{ Dou-gong } & \multirow{3}{*}{$\mathrm{D}$} & Corner set & $\mathrm{CS}$ & \multirow{3}{*}{\multicolumn{2}{|c|}{$\cdots$}} \\
\hline & & Lintel & LI & & \\
\hline & & Intermediate set & IS & & \\
\hline \multirow{8}{*}{ Roof } & \multirow{8}{*}{$\mathrm{R}$} & Ridge & RI & \multirow{3}{*}{\multicolumn{2}{|c|}{$\cdots$}} \\
\hline & & Beam & $\mathrm{BE}$ & & \\
\hline & & Tile & TI & & \\
\hline & & \multirow{5}{*}{ Decorative element } & \multirow{5}{*}{$\mathrm{DE}$} & Wen shou & WS \\
\hline & & & & Zou shou & ZS \\
\hline & & & & Chui shou & CS \\
\hline & & & & Tao shou & TS \\
\hline & & & & Others & $\mathrm{DO}$ \\
\hline
\end{tabular}

Note: this table is only an example of the coding design of flexible code segment and does not include the complete structural type of the Ming and Qing official-style architectures and does not represent the coding design of all Ming and Qing buildings. This paper focuses on the decorative components of the roof, the rest parts are simplified expression.

\section{Geo-Registration Mechanism for Template Library}

After the template library is established, the next task is to perform a geo-registration of the corresponding model of the roof decorative components in the library with the point cloud collected for any Ming and Qing official-style architecture. The process first detects the decorative components on the collected digital images based on the You Only Look Once v3 (YOLOv3) algorithm and determines the corresponding model in the template library according to the coding schema. Subsequently, the chosen 3D model in the template library is placed on the correct location of the roof using a point cloud matching algorithm; i.e., the Iterative Closest Point (ICP) algorithm [45]. Although the ICP point cloud registration method is proven accurate, it is also computationally demanding. Therefore, it is not conducive to process a large amount of data and is contrary to our intention to improve the degree of automation. It is worth noting that the registration results are better when the spatial location of the two sets of point clouds are close to each other. In this case, the target point cloud is likely to converge to a local minimum, which inspires us to propose a two-step mechanism with a coarse registration first and then a fine registration. This geo-registration mechanism not only overcomes the drawbacks of existing approaches relying on the manual operation of the template library, but also optimizes the model fitting results.

\subsection{Automatic Detection of Roof Decorative Components}

Prior to the geo-registration, the roof decorative components should be automatically detected on the collected images of any Ming and Qing official-style roof architecture. In this study, we adopt a deep learning algorithm for roof object detection that includes two major steps. First, because the Ming and Qing official-style architectures are famous and widely distributed in China and are very large in number, using the web crawler to obtain abundant Ming and Qing architectural roof decorative component images from the open network platforms is a good way to acquire this information. At the 
same time, a lightweight neural network was built to assist rapid image cleaning. After this, a dataset of roof decorative components can be successfully constructed through a few artificial discrimination and marks. Then, the YOLOv3 algorithm was applied to extract multi-level features of images and further integrated them into high-level semantic features of images to realize the detection of decorative components. The backbone of YOLOv3 is the Darknet-53 feature extractor. It has a stronger ability to extract image depth features and performs better on ImageNet datasets than Darknet-19, Resnet-101 and Resnet-152 [46,47]. Moreover, it achieves the highest floating-point calculation per second and higher efficiency [48]. Figure 6 shows the detection results of Chui shou and Zou shou on the roof of the Hall of Supreme Harmony (Beijing, China).

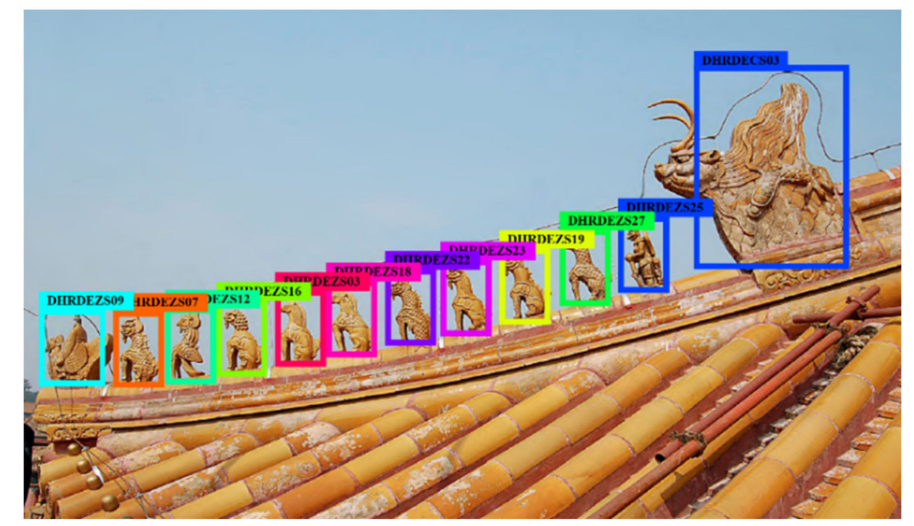

Figure 6. Detection results of decorative components (The Hall of Supreme Harmony) [22].

\subsection{Transformation of 3D Template Roof Model into 3D Point Cloud}

Once the roof object is successfully detected, the corresponding roof decorative components in the template library can be used to perform geo-registration. However, the 3D model cannot be used directly to match with the collected point cloud data. Therefore, it is necessary to transform the 3D model in the template library into a 3D point cloud. There may be a difference in terms of the point cloud density and the scale between the collected point cloud $P$ and the point cloud transformed from the template library $Q$; therefore, we intend to adjust the selected decorative component in the template library to be consistent with the collected point cloud. We reduce the density of the 3D point cloud of the decorative components to a specific density level that matches with the point cloud of the collected architecture prior to geo-registration. The ratio of the scales $S$ between two sets of point cloud data is shown in Equation (1).

$$
\frac{S_{P}}{S_{Q}}=\frac{D_{P}}{D_{Q}}
$$

In this equation, the $D_{P}$ is equal to the average distance from each point from collected point cloud $P$ to its centroid, and the $D_{Q}$ is equal to the average distance from each point from transformed point cloud $Q$ to the centroid.

\subsection{Coarse Registration Based on SAC-IA}

The coarse registration aims to determine an initial relative relationship between the two sets of point clouds based on a classical method named SAC-IA. SAC-IA was selected because this algorithm can ensure that the "match point cloud" and "target point cloud" roughly have the same spatial position. Because this algorithm uses Fast Point Feature Histogram (FPFH) features for point registration, compared with other algorithms (such as 3D scale-invariant feature transform (SIFT) feature matching algorithm), the computational efficiency is higher. Moreover, this algorithm adopts the matching strategy of random sampling, which can also realize registration quickly. Prior to the coarse registration, the FPFH features of each point were calculated, which can make the operation more efficient [33]. The SAC-IA can be divided into three steps. 
(1) Select $n$ points from the collected point cloud $P$ on the unknown Ming and Qing official-style architecture. In order to ensure that the selected points have different FPFH features, the distance between each selected point should be greater than a pre-defined minimum distance threshold $d$.

(2) In the transformed point cloud $Q$ derived from the template library, the SAC-IA first searches the points which have similar FPFH features of the selected points from collected point cloud $P$. Then, these points found within the searched points are selected as the corresponding points.

(3) Calculate the transformation matrix between the corresponding points, and then evaluate the performance of the coordinate transformation based on the sum of the distance error after using the corresponding points for transformation. In this paper, the sum function of the distance errors can be expressed as the Huber penalty measure $H$ as follows:

$$
f=\sum_{i=1}^{n} H\left(l_{i}\right)
$$

where,

$$
H\left(l_{i}\right)=\left\{\begin{array}{c}
\frac{1}{2} l_{i}^{2}, \mathrm{if}\left\|l_{i}\right\| \leq m l \\
\frac{1}{2} m l\left(2\left\|l_{i}\right\|-m l\right), \mathrm{if}\left\|l_{i}\right\|>m l
\end{array}\right.
$$

where $m l$ is a pre-defined threshold and $l_{i}$ is the difference of distance between the corresponding points. Figure $7 \mathrm{c}$ shows the initial registration result.

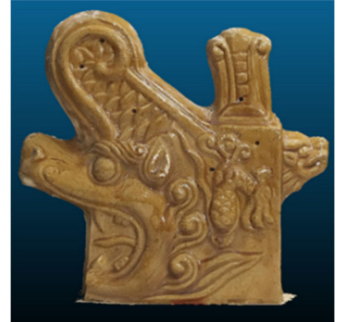

(a) Template model

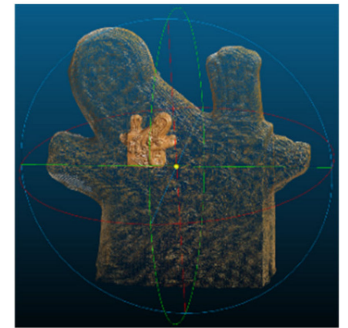

(b) Unregistered location

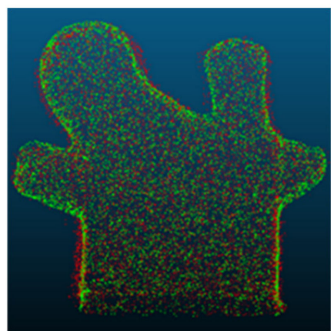

(c) Rough registration

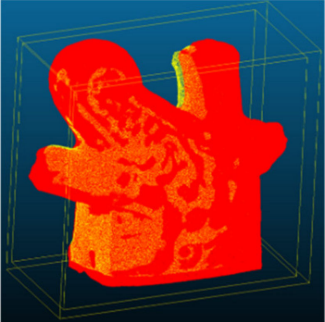

(d) Fine registration

Figure 7. The registration process of point cloud.

\subsection{Fine Registration Based on SICP}

The scale of the two sets of point clouds has been preliminarily unified after the coarse registration. However, their spatial positions are still not uniform and so this algorithm requires a further refinement. In this section, we adopt the improved SICP algorithm to register the transformed point cloud $Q$ to the collected point cloud P. SICP was selected because the algorithm is not limited to local matching but considers the overall scaling of two sets matching point cloud data, which made the result more accurate [34]. This algorithm can be expressed as Equation (4).

$$
\underset{S, R, t, j \in\left\{1,2, \ldots, N_{q}\right\}}{\operatorname{argmin}}\left(\sum_{i=1}^{N_{p}}\left\|\left(R S p_{i}+t\right)-q_{j}\right\| \begin{array}{l}
2 \\
2
\end{array}\right)
$$

In Equation (4), $S=\operatorname{diag}\left(s_{1}, s_{2}, \ldots, s_{i}, \ldots, s_{m}\right), s_{i} \in\left[a_{i}, b_{j}\right]$ is a non-zero scale matrix, $R$ is an orthogonal matrix, and $t$ is a translation vector. The implementation of this algorithm is an iterative process and is described as follows:

- Step 1: the correlation is established by the current transformation $\left(S_{k}, R_{k}, t_{k}\right)$. The calculation can be expressed as Equation (5).

$$
c_{k+1}(i)=\underset{j \in\left\{1,2, \ldots, N_{q}\right\}}{\operatorname{argmin}}\left(\left\|\left(R_{k} S_{k} p_{i}+t_{k}\right)-q_{j}\right\| \frac{2}{2}\right)
$$


- $\quad$ Step 2: make $S=\operatorname{diag}\left(s_{1}, s_{2}, \ldots, s_{i}, \ldots, s_{m}\right)$, and calculate the new transformation $\left(S_{k+1}, R_{k+1}, t_{k+1}\right)$. The calculation can be expressed as Equation (6).

$$
\left(S_{k+1}, R_{k+1}, t_{k+1}\right)=\underset{s_{j} \in\left[a_{j}, b_{j}\right], R, t}{\operatorname{argmin}}\left(\sum_{i=1}^{N_{p}}\left\|R S\left(R_{k} S_{k} p_{i}+t_{k}\right)+t-q_{c_{k+1}(i)}\right\| \begin{array}{l}
2 \\
2
\end{array}\right)
$$

- Step 3: repeat step 1 and step 2 until the changed amount $\Delta S=\left|S_{(k+1)}-S_{k}\right|$ is less than the threshold or the iteration number is more than the maximum iteration number. Figure $7 \mathrm{~d}$ shows the result of fine registration.

After the fine registration, the location information is calculated. The corresponding template 3D model from the template library can be retrieved and placed on the roof directly.

\section{A Case Study: A Classic Official-Style Architecture}

In this section, we use the constructed decorative components template library for the $3 \mathrm{D}$ reconstruction of the Ming and Qing official-style architecture roof without oversimplifying the details of the irregularly shaped decorative components. Here, we aim to demonstrate and verify the feasibility of our template library and the geo-registration mechanism by using a real modeling case. A classic Ming and Qing official-style architecture, which resides in the Forbidden City, was selected in the case study.

\subsection{Historical Background}

The Gate of Supreme Harmony was built in the 18th year of Yongle of the Ming Dynasty (1420), which is located south of the Forbidden City (see Figure 8). It is the largest palace gate in the Forbidden City and the main gate of the imperial palace of the Outer Court. The Gate of Supreme Harmony has nine rooms in width and four rooms in depth, with a construction area of $1300.00 \mathrm{~m}^{2}$. The roof is a double-eave gable-and-hip type and occupies more than half of the main building; the beams and ridges are covered with exquisite dragon patterns, in addition to the Chui shou, Tao shou and Wen shou being fixed on the ridges, and there are seven Zou shou and a fairy man on each hip ridge. In the Ming Dynasty, the Gate of Supreme Harmony was the place where the emperor received worship and reports from his subordinates, issued imperial edicts, and handled political affairs.

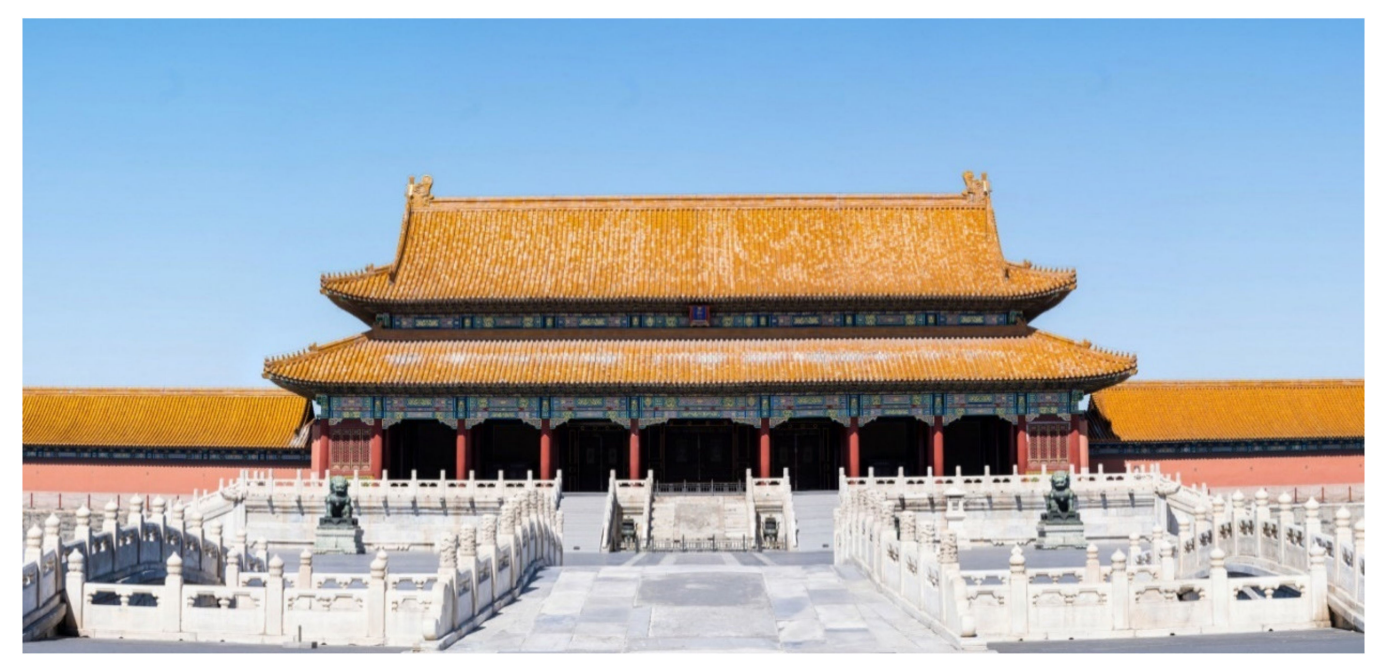

Figure 8. The Gate of Supreme Harmony [49]. 


\subsection{Data Collection}

In order to construct a 3D model, a complete 3D point cloud of the Gate of Supreme Harmony was collected. The survey was mainly carried out based on an image-based approach. A complete photogrammetric survey was conducted using an Unmanned Aerial Vehicle (UAV) to capture oblique images and a digital camera to collect nadir images. To improve the LoDs for a better documentation of the bottom part (including the walls and platform), the UAV data were integrated with the close-range digital images.

Regarding the UAV equipment, we selected the DJI Phantom4 quadcopter. The design of flight line is shown in Figure 9. The environment and weather will undoubtedly directly affect the collected data's quality. Therefore, it is necessary to select cloudless and sunny conditions to carry out the data collection work. Using a photogrammetric five-direction flight function, the angle of inclination is about 45-48 degrees. The down-looking images had a forward overlap and side overlap of approximately $60 \%$ and $30 \%$, respectively. The flight plan was implemented at an altitude of approximately 60 meters above the ground, and the camera equipped with a lens of focal length $8.8 \mathrm{~mm}$. Finally, a total of 225 oblique images were collected with a $2 \mathrm{~cm}$ ground resolution of pixels. DJI Phantom 4 is a professional photogrammetric system. Since this study uses small-area data collection, the POS system of this device can fully support the demand for photogrammetric accuracy, so no checkpoint is set up. The terrestrial acquisitions were recorded using a Nikon D750 full-frame digital camera equipped with a lens of focal length $17 \mathrm{~mm}$, and the ground resolution of the terrestrial photo acquisition pixel is $2 \mathrm{~cm}$. The shooting distance was controlled within $5 \mathrm{~m}$, and a total of 474 digital images were captured. Finally, the image acquired by the UAV and the terrestrial image were processed jointly by the bundle adjustment method.

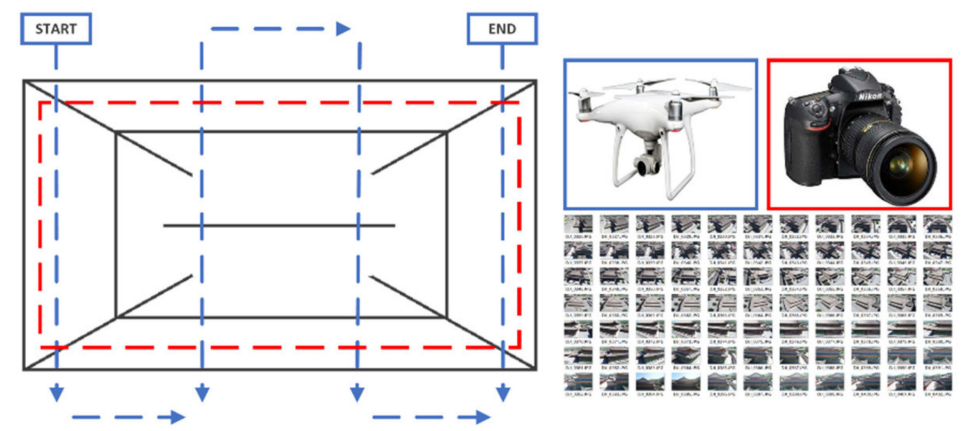

Figure 9. Airline and route design of the data collection.

The image data were registered and transformed into DIM point cloud data using the Context Capture Center software [50], and then the DIM point cloud data underwent the process of coloring, filtering, registration, and geo-referencing, etc. Through the point cloud accuracy evaluation method described in the paper [51], the platform and walls of The Gate of Supreme Harmony were used to evaluate the accuracy of the overall point cloud data. Figure 10 shows the result of the point cloud with a precision close to $\pm 3 \mathrm{~mm}$. 


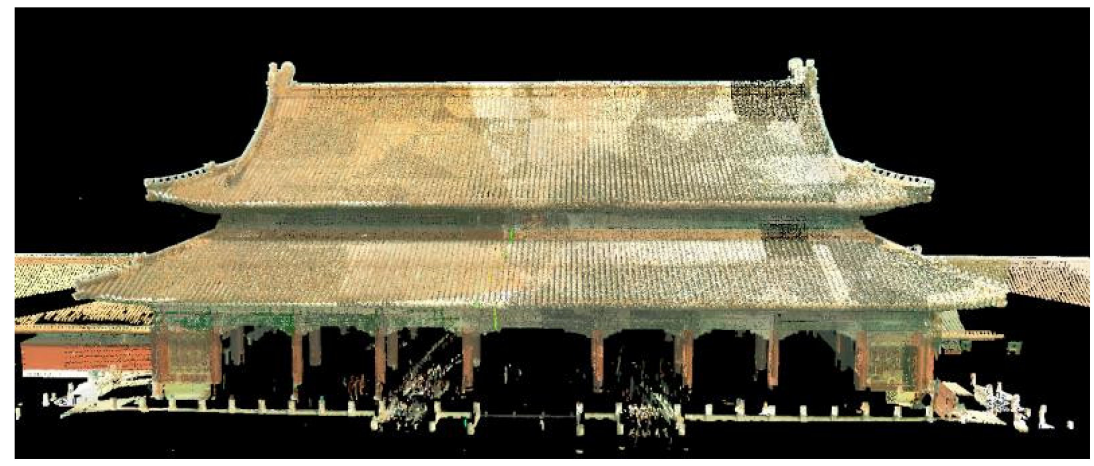

Figure 10. The final point cloud data obtained using an unmanned aerial vehicle (UAV) and digital camera.

\subsection{From the Point Cloud to the 3D Model}

Once the data collection was accomplished, the digital photos and generated point cloud of the Gate of Supreme Harmony underwent the proposed geo-registration process in order to generate a 3D model. The entire process was implemented based on the integrated development environment, Microsoft Visual Studio 2015, running on a DELL Precision 5510 with a CPU of Intel Core i7-2760QM $2.4 \mathrm{GHz}$, memory $2.98 \mathrm{~GB}$, and a Windows 10 operating system. Autodesk 3Ds Max was chosen as the 3D modeling environment.

Components, which follow simple design rules, such as ridges and tiles, can be directly modeled with the tools provided in the software. The accuracy of the modeled components can certainly meet the requirement of LoD 300. Regarding the decorative components, the performance of the YOLOv3 algorithm (i.e., YOLOv3, see Section 4.1. for more details) was tested by datasets obtained by web crawlers. A total of 572 samples were selected and tested, which contain 2809 roof decorative components of five categories of Ming and Qing official-style architecture. The overall Average Precision (AP) value of this algorithm reached 0.74. Under the conditions of the confidence threshold of 0.5 and the Intersection over Union (IOU) threshold of 0.6 , the test accuracy was $82.2 \%$ and the average single-image reasoning speed was $66 \mathrm{~ms}$ per frame. Both accuracy and speed can meet the application requirements of the geo-registration mechanism proposed in this paper, and then the corresponding component model was directly retrieved from the template library according to the coding schema. The result in this case is accurate compared with the actual situation of the roof (see Figure 11).

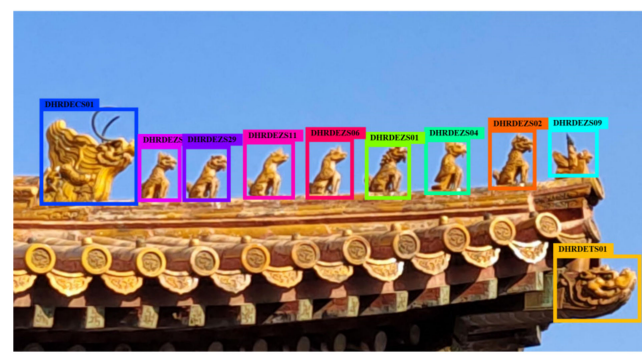

(a) The detection result of hip ridge

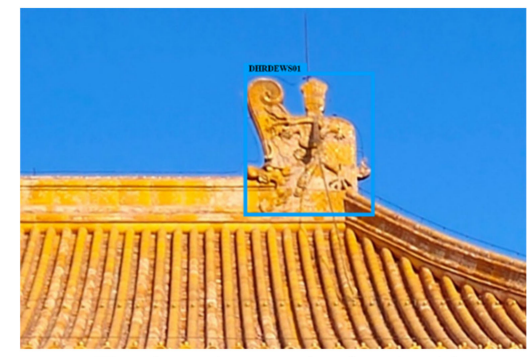

(b) The detection result of main ridge

Figure 11. The roof detection result based on You Only Look Once v3 (YOLOv3) algorithm.

Among all the detected roof decorative components, we selected the following representative components-Chui shou (DHRDECS01), Tao shou (DHRDETS01), Wen shou (DHRDEWS01), and Zou shou (DHRDEZS01) from the roof of the Gate of Supreme Harmony for further 3D modeling, as illustrated in Figure 12. In the YOLOv3 detection, the confidence values were $0.86,0.71,0.89$, and 0.88 , satisfying the threshold setting. 


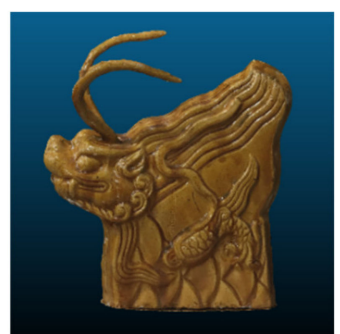

Chui shou (DHRDECS01)

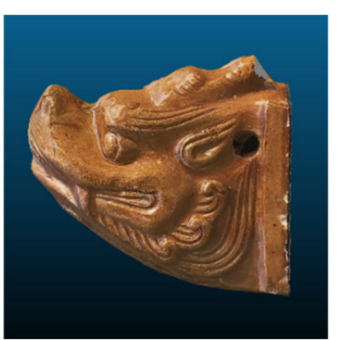

Tao shou (DHRDETS01)

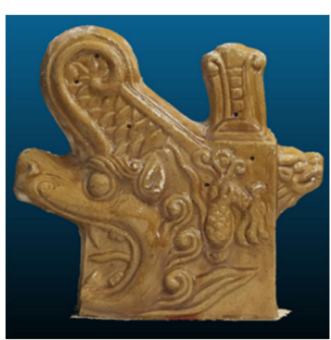

Wen shou

(DHRDEWS01)

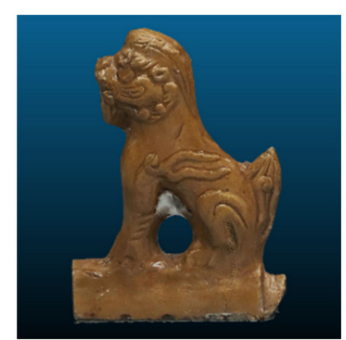

Zou shou

(DHRDEZS01)

Figure 12. Experimental component objects.

The corresponding 3D model detected in the template library was automatically placed on the roof of the Gate of Supreme Harmony according to the geo-registration mechanism. Since the point cloud density is an important parameter that affects the final registration result, in this experiment we randomly diluted the 3D model of the template library into a set of point clouds by $10 \%, 25 \%, 50 \%$ (the total number of point clouds is 10,000), and evaluated their registration results. This approach also simulated point clouds collected from different data acquisition devices with different LoDs. Figure 13 shows the best registration results with 10,000 data points. The accuracy and time consumption of this process are further analyzed below.

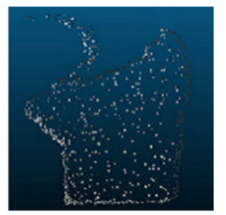

Chui shou (DHRDECS01)

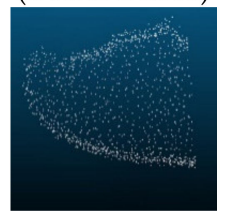

Tao shou (DHRDETS01)

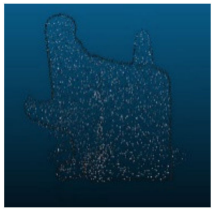

Wen shou (DHRDEWS01)

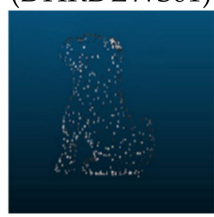

Zou shou (DHRDEZS01)

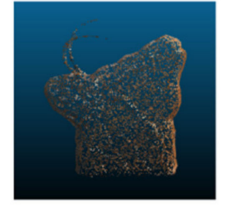

Chui shou (DHRDECS01)

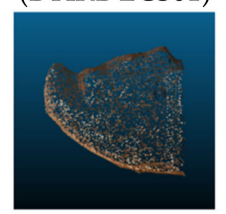

Tao shou (DHRDETS01)

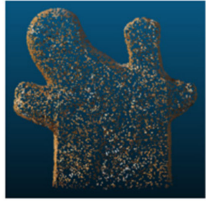

Wen shou (DHRDEWS01)

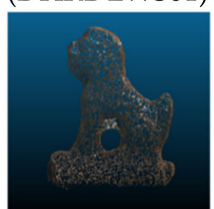

Zou shou (DHRDEZS01)

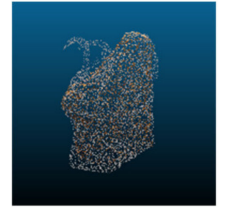

Chui shou (DHRDECS01)

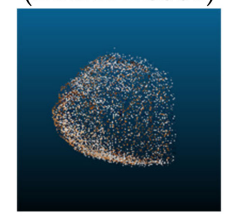

Tao shou (DHRDETS01)

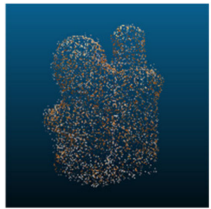

Wen shou (DHRDEWS01)

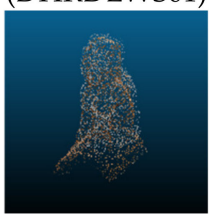

Zou shou (DHRDEZS01)

(c) Results of registration

Figure 13. Experimental component objects with 10,000 points reserved.

The experimental results of 3D reconstruction were assessed based on computing the Root Mean Square (RMS) error. As shown in Figure 14, the average value of RMS was less than $0.02 \mathrm{~m}$ most of the time for the four decorative components. Thus, the registration results certainly fulfilled the construction requirement of modeling the precision of LoD 300. When the number of points was diluted into 1000 points from the roof decorative component 3D model retrieved from the template library, the registration result was the worst with an average RMS error of $0.019 \mathrm{~m}$. When the number of points was diluted to 10,000, the registration result yielded to the best with an average RMS error of less than $0.01 \mathrm{~m}$. Although the RMS error of the registration slightly reduced with the increased number of points, the reduction was not significant after multiple experiments, meaning that the point density has no influential impact on the results. It thus proves that the higher the point density of the registered object is, the better the registration accuracy that can be achieved. Among the four experimental roof decorative components, the registration result of Chui shou was the worst. Comparing to the other components, Chui shou has the most complex structure. Therefore, it can be inferred that the complexity of components also affects the registration result. When the number of points yielded to 10,000, the RMS of Zou shou dramatically increased. We suspect that the registration is misleading due 
to the fixed tile found in the Zou shou. Therefore, when establishing the template library, we should fully consider the actual situation and enrich its content to cater different decorative components. Moreover, the processing time was stable or had a slight increase with an increase in the number of points. The experimental results show that not only the accuracy of the registration results can meet the requirements of reconstruction, but also the working efficiency can be guaranteed under the condition of stable computational time consumption.

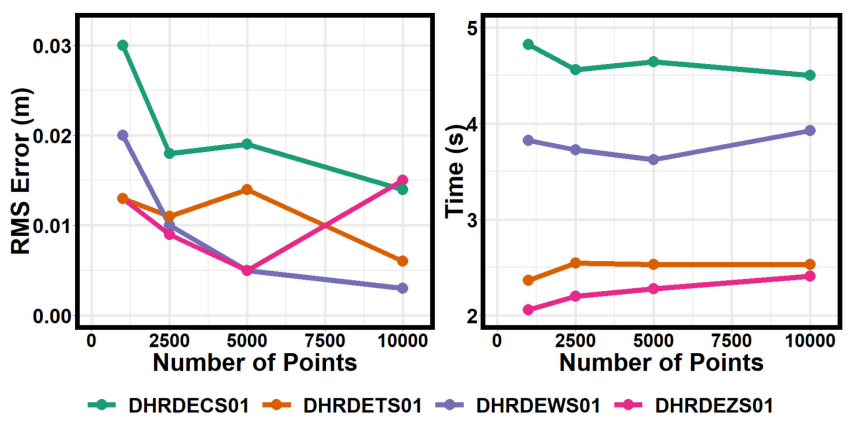

Figure 14. The experimental results.

The final 3D roof model of the gate of Supreme Harmony was made up of the following components: 2 ceilings, 1 beam, 12 ridges, 6326 tiles and 58 decorative components, as shown in Figure 15. The rest of the building structures were reconstructed according to the pattern books manually with reference modeling tools, which offers a good representation of the proportion and spatial relationship between these structures of the Gate of Supreme Harmony.

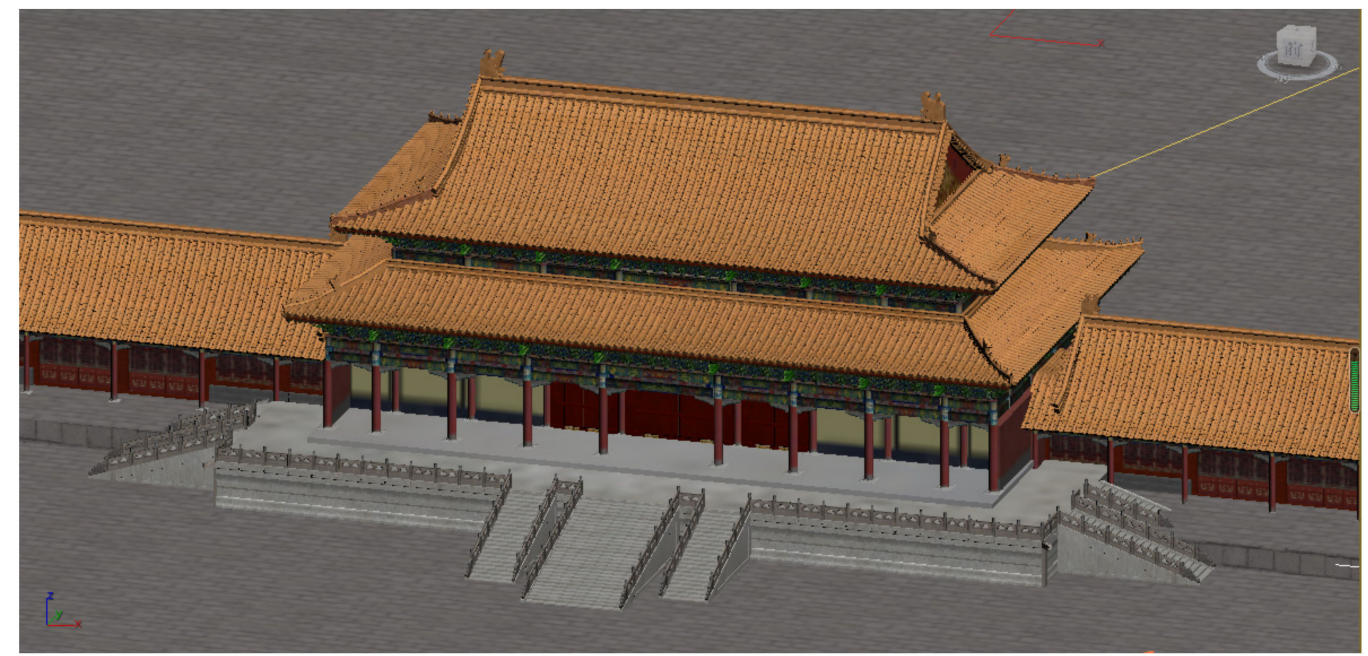

Figure 15. The final 3D model of the Gate of Supreme Harmony.

\section{Conclusions}

In this study, we establish a roof decorative components template library for the Ming and Qing official-style architectures and propose a 3D reconstruction method based on an automatic geo-registration mechanism combined with the template library. The contribution of this work is twofold. First, based on the proposed geo-registration, the roof decorative components can be positioned, located, and scaled correctly on the roof of any surveyed Ming and Qing official-style architecture through matching a corresponding component from the template library. Second, our template library is of high universality and can facilitate the 3D reconstruction of most of the Ming and Qing official-style architectures' roofs. The core idea of this work is to ensure the details of each roof decorative component can be accurately represented under automatic 3D 
reconstruction. In addition, this method allows an accurate and efficient 3D modeling of any historic architecture collected by laser scanning or photogrammetric image data. The constructed 3D model can be considered as a reasonable representation and interpretation of the architecture with different levels of complexity (e.g., ridges, simple structures, decorative components, complex structures, etc.).

The proposed strategy not only provides an effective method for the $3 \mathrm{D}$ reconstruction of the Ming and Qing official-style architectures' roof, but can also be applied to other building components or parts, and other similar architectures which follow certain design rules, for instance, the Dou-gong of the Song dynasty architectures, the dome of Islamic architectures, the statues of European churches, and so on. However, it is worth noting the topological relationships between the "component to component" and "component to architecture", which were not addressed in this paper. The topology is especially important for creating physical copies of the scanned components (e.g., using 3D printing), which will be a particular focus of further study.

The content of the template library is currently under expansion in order to cover more roof decorative components, as well as other architectural components of Ming and Qing official architectures. In future, it is intended to build an interoperable platform with the template library for supporting fully- or semiautomated process of detection/matching and geo-registration, by following related standards. Through information sharing and exchange among different HBIM systems, the template library can be further expanded and enriched, and thus provides an effective way for its further development and benefits from a wider application. As such, the template library can be extended to not only contain roof decorative components, but also cover various types of roof components (roof ridges, tiles, etc.), and even all parts of the whole building. The variety of component forms and rich datasets also provide better test conditions for the success/failure rates detection of the geo-registration mechanism. Further, such a collaborative platform can certainly improve the feasibility for the long-term management of the corresponding ancient architectural heritage and HBIM.

Author Contributions: Pengpeng Huo conducted the entire research process and wrote the paper; Miaole Hou proposed the framework of the decorative component template library; Youqiang Dong conceived the entire research process, guided the students to complete the research and participated in the experiment; Aiqun Li provided historical knowledge; Yuhang Ji participated in the research process and the experiment; Songnian Li guided the logical structure of the paper and contributed to the review-editing-revision of the manuscript. All authors have read and agreed to the published version of the manuscript.

Funding: This research was supported by the National Key R\&D Program of China (NO.2019YFC1520800), Great Wall Scholars Training Program Project of Beijing Municipality Universities (CIT\& TCD20180322), Beijing Key Laboratory of Urban Spatial Information Engineering (NO.2020214) and Beijing Postdoctoral Research Foundation.

Acknowledgments: We would like to thank Wai Yeung Yan from The Hong Kong Polytechnic University for his invaluable help to the author, his constructive suggestions helped us to have more good research ideas.

Conflicts of Interest: The authors declare no conflict of interest.

\section{References}

1. Kostof, S. A History of Architecture: Settings and Rituals; Oxford University Press: New York, NY, USA, 1995.

2. Naranjo, J.M.; Parrilla, Á.; de Sanjosé, J.J. Geometric characterization and interactive 3D visualization of historical and cultural heritage in the province of Cáceres (Spain). Virtual Archaeol. Rev. 2018, 9, 1-11. [CrossRef]

3. Calin, M.; Damian, G.; Popescu, T.; Manea, R.; Erghelegiu, B.; Salagean, T. 3D modeling for digital preservation of Romanian heritage monuments. Agric. Agric. Sci. Procedia 2015, 6, 421-428. [CrossRef]

4. Gomes, L.; Bellon, O.R.P.; Silva, L. 3D reconstruction methods for digital preservation of cultural heritage: A survey. Pattern Recognit. Lett. 2014, 50, 3-14. [CrossRef]

5. Perera, G.S.N.; Maas, H.G. Cycle graph analysis for 3D roof structure modelling: Concepts and performance. ISPRS J. Photogramm. Remote Sens. 2014, 93, 213-226. [CrossRef]

6. Li, D.; Xiao, X.; Guo, B. Oblique image based automatic aerotriangulation and its application in $3 \mathrm{~d}$ city model reconstruction. Geomat. Inf. Sci. Wuhan Univ. 2016, 41, 711-721. [CrossRef] 
7. Ren, P.; Wang, Y.; Zhou, M.; Wu, Z.; Zhou, P.; Zhang, J. Data-driven modeling for chinese ancient architecture. Presence Teleoperators Virtual Environ. 2018, 26, 389-401. [CrossRef]

8. Nishida, G.; Garcia-Dorado, I.; Aliaga, D.G.; Benes, B.; Bousseau, A. Interactive sketching of urban procedural models. Acm Trans. Graph. (TOG) 2016, 35, 1-11. [CrossRef]

9. Dore, C.; Murphy, M. Integration of Historic Building Information Modeling (HBIM) and 3D GIS for recording and managing cultural heritage sites. In Proceedings of the 2012 18th International Conference on Virtual Systems and Multimedia, Milan, Italy, 2-5 September 2012; pp. 369-376.

10. Hohmann, B.; Havemann, S.; Krispel, U.; Fellner, D. A GML shape grammar for semantically enriched 3D building models. Comput. Graph. 2010, 34, 322-334. [CrossRef]

11. Xue, F.; Lu, W.; Chen, K.; Webster, C.J. BIM reconstruction from 3D point clouds: A semantic registration approach based on multimodal optimization and architectural design knowledge. Adv. Eng. Inform. 2019, 42, 100965. [CrossRef]

12. Kobyshev, N.; Riemenschneider, H.; Bodis-Szomoru, A.; Van Gool, L. Architectural decomposition for 3D landmark building understanding. In Proceedings of the 2016 IEEE Winter Conference on Applications of Computer Vision (WACV), Lake Placid, NY, USA, 7-10 March 2016; pp. 1-10.

13. Wang, C.; Cho, Y.K.; Kim, C. Automatic BIM component extraction from point clouds of existing buildings for sustainability applications. Autom. Constr. 2015, 56, 1-13. [CrossRef]

14. Haala, N.; Kada, M. An update on automatic 3D building reconstruction. ISPRS J. Photogramm. Remote Sens. 2010, 65, 570-580. [CrossRef]

15. Musialski, P.; Wonka, P.; Aliaga, D.G.; Wimmer, M.; Van Gool, L.; Purgathofer, W. A survey of urban reconstruction. In Computer Graphics Forum; Blackwell Publishing Inc.: Malden, MA, USA; pp. 146-177. [CrossRef]

16. Liu, J.; Wu, Z.K. Rule-based generation of ancient Chinese architecture from the Song dynasty. J. Comput. Cult. Herit. (JOCCH) 2015, 9, 1-22. [CrossRef]

17. Liu, J. Component-driven pocedural modeling for ancient Chinese architecture of the Qing Dynasty. Int. J. Archit. Herit. 2018, 12, 280-307. [CrossRef]

18. Li, L.; Tang, L.; Zhu, H.; Zhang, H.; Yang, F.; Qin, W. Semantic 3D modeling based on CityGML for ancient Chinese-style architectural roofs of digital heritage. ISPRS Int. J. Geo-Inf. 2017, 6, 132. [CrossRef]

19. Fassi, F.; Achille, C.; Fregonese, L. Surveying and modelling the main spire of Milan Cathedral using multiple data sources. Photogramm. Rec. 2011, 26, 462-487. [CrossRef]

20. Barazzetti, L. Parametric as-built model generation of complex shapes from point clouds. Adv. Eng. Inform. 2016, 30, 298-311. [CrossRef]

21. Liang, S. A Pictorial History of Chinese Architecture; China Architecture \& Building Press: Beijing, China, 1984.

22. Zhang, K. Three Hundred Years of the Hall of Supreme Harmony; Science Press: Beijing, China, 2016.

23. Li, J. Yingzao Fashi; Song Dynasty: China, 1103.

24. Wang, F. Ancient Building Tile Engineering Technology; Chemical Industry Press: Beijing, China, 2013.

25. Poloprutský, Z. Parametric modelling for hbim: Design of window library for rural building. Civ. Eng. J. 2019, 52, 620-630. [CrossRef]

26. Murphy, M.; Mcgovern, E.; Pavia, S. Historic Building Information Modelling-Adding intelligence to laser and image based surveys of European classical architecture. ISPRS J. Photogramm. Remote Sens. 2013, 76, 89-102. [CrossRef]

27. Baik, A.; Alitany, A.; Boehm, J.; Robson, S. Jeddah Historical Building Information Modelling “JHBIM"-Object Library. In Proceedings of the ISPRS Technical Commission V Symposium, Riva del Garda, Italy, 23-25 June 2014.

28. Dore, C.; Murphy, M. Semi-automatic modelling of building facades with shape grammars using historic building information modelling. Int. Arch. Photogramm. Remote Sens. Spat. Inf. Sci. 2013, 5, W1. [CrossRef]

29. Murphy, M.; Corns, A.; Cahill, J.; Eliashvili, K.; Chenau, A.; Pybus, C.; Shaw, R.; Devlin, G.; Deevy, A.; Truong-Hong, L. Developing historic building information modelling guidelines and procedures for architectural heritage in ireland. Int. Arch. Photogramm. Remote Sens. Spat. Inf. Sci. 2017, 42, 539-546. [CrossRef]

30. Oreni, D.; Brumana, R.; Della Torre, S.; Banfi, F.; Previtali, M. Survey turned into HBIM: The restoration and the work involved concerning the Basilica di Collemaggio after the earthquake (L'Aquila). ISPRS Ann. Photogramm. Remote Sens. Spat. Inf. Sci. 2014, 2, 267. [CrossRef] 
31. Quattrini, R.; Malinverni, E.S.; Clini, P.; Nespeca, R.; Orlietti, E. From tls to hbim. high quality semantically-aware 3d modeling of complex architecture. Int. Arch. Photogramm. Remote Sens. Spat. Inf. Sci. 2015, XL-5/W4, 367-374. [CrossRef]

32. Redmon, J.; Farhadi, A. Yolov3: An incremental improvement. arXiv 2018, arXiv:1804.02767.

33. Rusu, R.B.; Blodow, N.; Beetz, M. Fast point feature histograms (FPFH) for 3D registration. In Proceedings of the 2009 IEEE International Conference on Robotics and Automation, Kobe, Japan, 12-17 May 2009; pp. 3212-3217.

34. Bouaziz, S.; Tagliasacchi, A.; Pauly, M. Sparse iterative closest point. In Computer Graphics Forum; Blackwell Publishing Ltd.: Oxford, UK, 2013; pp. 113-123.

35. Liang, S. Qing Structural Regulations; Society for the Study of Chinese Architecture: Lizhuang, China, 1934.

36. The Civil Engineering \& Architectural Society of Beijing. Repair and Construction Technology of Chinese Ancient Architecture; China Architecture \& Building Press: Beijing, China, 2006.

37. Liu, C. The Forbidden City; Tsinghua University Press: Beijing, China, 2012.

38. The Qing Labor Department. Methods of Construction; Qing Dynasty: China, 1734.

39. Chiabrando, F.; Lo Turco, M.; Rinaudo, F. Modeling the decay in an HBIM starting from 3D point clouds. A followed approach for cultural heritage knowledge. Int. Arch. Photogramm. Remote Sens. Spat. Inf. Sci. 2017, 42, 605-612. [CrossRef]

40. American Institute of Architects. Level of Development Specification. Available online: https://bimforum. org/lod (accessed on 17 June 2020).

41. Bloomberg, M.R.; Burney, D.J.; Resnick, D. BIM Guidelines; New York City Department of Design and Construction: New York, NY, USA, 2012; pp. 1-57.

42. Lombardini, N.; Cantini, L. Non-standardized data in the BIM process. The management of construction systems data in the cultural heritage conservation. In Proceedings of the PROHITEC'17-3rd International Conference on Protection of Historical Constructions, Lisbon, Portugal, 12-15 July 2017; IST Press: Lisbon, Portugal, 2017; pp. 1-12.

43. Banfi, F. BIM Orientation: Grades of Generation and Information for Different Type of Analysis and Management Process; The International Archives of the Photogrammetry, Remote Sensing and Spatial Information Sciences, Canada. 2017. Available online: https://www.int-arch-photogramm-remote-sensspatial-inf-sci.net/XLII-2-W5/57/2017/ (accessed on 28 September 2020).

44. Brumana, R.; Banfi, F.; Cantini, L.; Previtali, M.; Della Torre, S. Hbim level of detail-geometry-Accuracy and survey analysis for architectural preservation. In Proceedings of the 2nd International Conference of Geomatics and Restoration, GEORES 2019, Milan, Italy, 8-10 May 2019; Copernicus GmbH: Göttingen, Germany, 2019; pp. 293-299. [CrossRef]

45. Besl, P.J.; Mckay, N.D. Method for registration of 3-D shapes. In Sensor Fusion IV: Control Paradigms and Data Structures; International Society for Optics and Photonics: Bellingham, WA, USA, 1992; pp. 586-606. [CrossRef]

46. Benjdira, B.; Khursheed, T.; Koubaa, A.; Ammar, A.; Ouni, K. Car detection using unmanned aerial vehicles: Comparison between faster r-cnn and yolov3. In Proceedings of the 2019 1st International Conference on Unmanned Vehicle Systems-Oman (UVS), Muscat, Oman, 5-7 February 2019; pp. 1-6.

47. Park, J.H.; Hwang, H.W.; Moon, J.H.; Yu, Y.; Kim, H.; Her, S.B.; Srinivasan, G.; Aljanabi, M.N.A.; Donatelli, R.E.; Lee, S.J. Automated identification of cephalometric landmarks: Part 1-Comparisons between the latest deep-learning methods YOLOV3 and SSD. Angle Orthod. 2019, 89, 903-909. [CrossRef]

48. Zhang, X.; Yang, W.; Tang, X.; Liu, J. A fast learning method for accurate and robust lane detection using two-stage feature extraction with YOLO v3. Sensors 2018, 18, 4308. [CrossRef]

49. The Palace Museum. The Gate of Supreme Harmony. Available online: https://img.dpm.org.cn/explore/ building/236439.html (accessed on 22 April 2020).

50. Bentley Software Products for Infrastructure Professionals. Available online: https://www.bentley.com/en/ products/brands (accessed on 9 September 2020).

51. Cavegn, S.; Haala, N.; Nebiker, S.; Rothermel, M.; Tutzauer, P. Benchmarking high density image matching for oblique airborne imagery. Int. Arch. Photogramm. Remote Sens. Spat. Inf. Sci. 2014. [CrossRef] 
(C) 2020 by the authors. Licensee MDPI, Basel, Switzerland. This article is an open access article distributed under the terms and conditions of the Creative Commons Attribution (CC BY) license (http://creativecommons.org/licenses/by/4.0/). 